
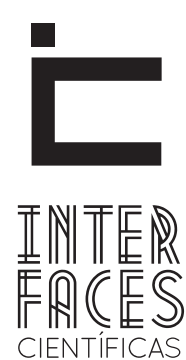

SAÚDE E AMBIENTE

\title{
ENDODONTIA: TEOR DE CLORO LIVRE E PH EM SOLUÇ̃̃ES COMERCIAIS DE HIPOCLORITO DE SÓDIO UTILIZADOS EM CONSULTÓRIOS
}

Breno de Araujo Batista ${ }^{1}$

Juliana Cordeiro Cardoso ${ }^{3}$
Cristina Reiss de Araujo $^{2}$

\section{RESUMO}

O hipoclorito de sódio é considerado irrigante de primeira escolha entre os cirurgiões dentistas do mundo inteiro, devido as suas excelentes propriedades. No entanto, para que o mesmo possa exercer tais propriedades, é necessário que o produto apresente uma boa qualidade. 0 propósito deste estudo foi verificar a qualidade de diferentes marcas de hipoclorito de sódio por meio da avaliação do teor de cloro livre e $\mathrm{pH}$ durante o uso e armazenamento. Utilizou-se seis soluções de hipoclorito de sódio na concentração de $2-2,5 \%$ de diferentes marcas e procedências para verificação do teor de cloro livre e pH durante 90 dias de estudo. Com relação ao teor de cloro livre, os melhores resultados foram obtidos pelas soluções S4 e S5, seguido por S6 e S3 e os piores pelas soluções S1 e S2. Além disso, todas apresentaram $\mathrm{pH}$ alcalino durante os 90 dias. A perda de cloro de todas as amostras é dependente do fator tempo e é importante que o cirurgião-dentista adquira confiança na origem do produto que está sendo utilizado, além de um rigoroso controle de qualidade pelos órgãos fiscalizadores.

\section{PALAVRAS-CHAVE}

Hipoclorito de Sódio. Cloro Disponível. PH. 


\section{ABSTRACT}

The sodium hypochlorite is considered irrigant of choice among dentists worldwide, due to its excellent properties. However, to be enabling to use those properties, a good product's quality is necessary. The purpose of this study was to assess the quality of different sodium hypochlorite brands by evaluating the content of free chlorine and $\mathrm{pH}$ during use and storage. Six solutions of sodium hypochlorite at a concentration of 2-2,5\% from different brand and origins were used to measure the free chlorine and the $\mathrm{pH}$ during the 90 days of study. Of the free chlorine content, the best re-

\section{RESUMEN}

El hipoclorito de sodio es considerado como un compuesto que irriga en primera línea, entre los dentistas de todo el mundo, debido a sus excelentes propiedades. Sin embargo, para estar habilitado para usar esas propiedades, es necesario que sea un producto de buena calidad. El propósito de este estudio, ha sido lo de evaluar la calidad de las diferentes marcas de hipoclorito de sodio, a través de una prueba físico-química en diferentes momentos de uso y almacenamiento. Métodos - seis soluciones de hipoclorito de sodio a una concentración de $2-2,5 \%$ a partir de diferentes orígenes marca y se utilizaron para medir el cloro disponible y el $\mathrm{pH}$ durante los 90 días de estudio. Con relación al con- sults were obtained by S4 and S5 solutions, followed by $\mathrm{S} 3$ and $\mathrm{S} 6$ and the worst were S1 and S2 solutions. In addition, all the solutions showed alkaline $\mathrm{pH}$ during the 90 days. The chlorine loss of all samples is time-dependent and it is important that dentist trust in the product's origin used, also a strict quality control by the by inspection authorities.

\section{KEYWORDS}

Sodium Hypochlorite. Free Chlorine. $\mathrm{pH}$. tenido de cloro disponible, los mejores resultados se obtuvieron mediante soluciones S4 y S5, S6 y seguido por S3 y el peor eran soluciones S1 y S2. Además, todas las soluciones mostraron $\mathrm{pH}$ alcalino durante los 90 días. Se concluyó que la pérdida de cloro de todas las muestras está directamente relacionada con el factor tiempo y es importante que el dentista confié en el origen del producto usado, y también que haya un estricto control de calidad por los departamentos gubernamentales.

\section{PALABRAS CLAVE}

Hipoclorito de sódio. El cloro disponible. $\mathrm{pH}$. 


\section{INTRODUCÇÃO}

Há uma variedade enorme de substâncias químicas que podem ser utilizadas durante o preparo do canal radicular. Entre essa gama de produtos, o hipoclorito de sódio, nas suas diferentes concentrações, constitui a primeira escolha mundial entre os cirurgiões dentistas, devido as suas propriedades altamente desejáveis como coadjuvante do preparo químico-mecânico do canal radicular (BORIN et al., 2007, SIRTES et al., 2005, SÓ et al., 2004). Além disso, ele também é usado como agente de limpeza e desinfecção de instrumentos e equipamentos médicos e odontológicos (MARCHESAN et al., 1998).

Devido ao seu mecanismo de ação, a solução é capaz de promover alterações celulares biossintéticas e destruição de fosfolipídios, pela formação de cloraminas que interferem no metabolismo celular, pela ação oxidante, com inibição enzimática irreversível nas bactérias e pela degradação de ácidos graxos e lipídeos (ESTRELA et al., 2002, NICOLETTI et al., 1995).

Diante deste mecanismo, sobressaem as propriedades de baixa tensão superficial, desodorizante, clareadora, lubrificante, detergente, bactericida, solvente de matéria orgânica e pH alcalino (ESTRELA et al., 2002, CARVALHO et al., 2003).

Por ser uma solução clorada, o hipoclorito apresenta uma acentuada instabilidade. Diversos são os fatores que interferem: temperatura, presença de luz, de íons metálicos, matéria orgânica, concentração, armazenamento, transporte, contato com o ar e pH (LOPES; SIQUEIRA JR. 2004; TANOMARU et al., 2005). Há uma perda de cloro disponível e, por isto o profissional deve usar soluções recentemente preparadas e armazenadas em vidro âmbar firmemente fechados, independentes de sua procedência e o mais próximo possível da data de fabricação (CARVALHO et al., 2003).

Em alguns países, com especial destaque para os Estados Unidos, o emprego de água sanitária como fonte de hipoclorito de sódio para irrigação endodôntica é amplamente difundido e utilizado entre os cirurgiões-dentistas, numa concentração de 5,25\% (LUDWIG et al., 2006). No Brasil, essa solução é encontrada numa concentração de 2-2,5\% em supermercados e tem se mostrado uma alternativa viável devido ao menor custo deste, sendo inclusive objeto de pesquisas (NICOLETTI; BAEZA; MAGALHÃES, 1995; RUTALA et al., 1998).

Segundo Rutala e outros autores (1998), o ideal seria que as soluções fossem preparadas diariamente, uma vez que quanto mais recente, maior sua eficácia. $\mathrm{Na}$ literatura há certa divergência quanto ao prazo de validade, mas a maioria dos autores sugere estocar por até três meses (BORIN; OLIVEIRA; BECKER, 2007). Além disso, para que as soluções de hipoclorito de sódio possam desempenhar sua total efetividade é necessário que a concentração seja a mais fiel à que está indicada no rótulo do fabricante, apresentando boa qualidade (REISS et al., 2006).

Pécora e outros autores (1987) e Siqueira (2000), em seus estudos, demonstraram que o hipoclorito de sódio armazenado em temperatura ambiente e exposto diretamente à luz solar sofreu maior perda de cloro do que quando armazenado em geladeira por 122 dias.

Pécora; Murgel; Savioli; Costa; Vansan (1987) avaliaram a influência da embalagem, luminosidade e de ausência de tampa na estabilidade da solução de hipoclorito de sódio a 2,6\%. Verificou que quando em presença de luz, os recipientes mais adequados foram os de vidro âmbar e plástico verde opaco. Os recipientes tampados mantiveram melhor a concentração de cloro do que os destampados (CLARKSON; PODLICH; SAVAGE, 2003).

As soluções de hipoclorito de sódio sofrem diversas influências que podem alterar suas propriedades, principalmente quanto à dissolução de tecido orgânico e antimicrobiana. Diversos estudos analisaram o teor de cloro livre dessas soluções em diferentes localidades e constataram que a maior parte não apresentava um teor 
de cloro livre dentro dos padrões especificados nas embalagens (BARATTO FILHO et al., 2001; CARVALHO et al., 2003; FILHO et al., 2002).

Siqueira (2000) avaliou a influência do pH sobre a estabilidade química de quarenta soluções de hipoclorito de sódio a 0,5\% durante 122 dias. Verificaram que as soluções ajustadas em pH 9 e armazenadas sob refrigeração deveriam ser utilizadas, devido a estabilidade química apresentada.

No processo de manutenção da estabilidade química do produto, há de se considerar que o pH exerce influência sobre o ácido hipocloroso, decorrente da hidrólise do hipoclorito de sódio, que é o responsável direto pela maior liberação de cloro ativo quando aquele for próximo do neutro e progressivamente menor em quantidade à medida que se eleva o mesmo (SÓ et al., 2004).

Com a intenção de manter um controle de qualidade rigoroso, alguns estudos avaliaram o pH das soluções de hipoclorito de sódio e constataram que quando em pH básico ou alcalino, as soluções se tornam mais estáveis, com lenta liberação de cloro e maior tempo de vida útil (BORIN; OLIVEIRA; BECKER, 2007; ESTRELA, et al., 2002; REISS, 2006).

Baseado na literatura pertinente, o propósito deste estudo foi verificar a qualidade de diferentes marcas de hipoclorito de sódio na concentração de 2-2,5\% (águas sanitárias), por meio de uma avaliação físico-química em diferentes tempos de uso e acondicionamento.

\section{MATERIAL E MÉTODO}

Foram utilizadas 4 (quatro) soluções comerciais de hipoclorito de sódio com rótulo indicando concentração de cloro livre entre 2 e 2,5\%, foram adquiridas diretamente das fábricas situadas no Estado de Sergipe em suas embalagens originais (S1, S2, S3 e S6). Além destas soluções, outras duas (S4 e S5) foram adquiridas em supermercados com a mesma concentração, sendo utili- zadas como controle por se tratar de marcas conceituadas nacionalmente e produzidas em outro Estado. Todos os fabricantes apresentaram como prazo de validade do produto o período de 6 meses e embalagens plásticas. Ressalta-se, também, que todas as amostras foram doadas com autorização dos fabricantes (S1, S2, S3 e S6), exceto as soluções S4 e S5.

As soluções foram armazenadas em geladeira no período noturno (12 horas) e mantidas abertas durante o dia, em temperatura ambiente (12 horas), a fim de mimetizar a utilização das mesmas em consultório odontológico. Durante o dia, eram protegidas por uma fina camada de gaze a fim de evitar possível contaminação para não haver contaminação.

\section{TEOR DE CLORO LIVRE}

As análises do teor de cloro livre e determinação do $\mathrm{pH}$ das soluções foram realizadas durante 90 dias após a abertura da embalagem no Laboratório de Produtos Naturais e Sintéticos (LPNS) do Instituto de Tecnologia e Pesquisa (ITP) da Universidade Tiradentes-Sergipe.

A avaliação do teor de cloro livre das soluções foi feita pelo método da iodometria. A solução titulante de tiossulfato de sódio $0,1 \mathrm{~N}$ foi preparada, diluindo $50 \mathrm{~g}$ de tiossulfato de sódio em $2 \mathrm{~L}$ de água destilada em balão volumétrico. Após homogeneização, a mesma foi mantida em repouso por 24 horas em geladeira e retirada com uma hora de antecedência de cada avaliação. Esta solução foi padronizada utilizando como padrão primário dicromato de potássio e o fator de correção do titulante determinado. Além do titulante foram preparados $500 \mathrm{~mL}$ de ácido acético a $6 \%(\mathrm{v} / \mathrm{v})$, e solução de amido a $1 \%(\mathrm{~m} / \mathrm{m})$.

Em um erlenmeyer de $250 \mathrm{~mL}$ foi transferido $4 \mathrm{~mL}$ da solução de hipoclorito de sódio de 2 a 2,5\%, homogeneizados com $50 \mathrm{~mL}$ de água destilada, $15 \mathrm{~mL}$ da solução de ácido acético $6 \%$ e $3 \mathrm{~g}$ de iodeto de potássio. A solução resultante de coloração marron foi titulada com a solução padrão de tiossulfato de sódio $0,1 \mathrm{~N}$, sob 
agitação constante, até que a mesma resultasse numa coloração amarelo-clara. Em seguida adicionou-se 3 $\mathrm{mL}$ do indicador (solução de amido a 1\%) até a solução adquirir a coloração azul-violácea. A titulação foi então retomada pela adição do tiossulfato de sódio até a solução tornar-se transparente. 0 volume de tiossulfato de sódio consumido foi utilizado para o cálculo do teor de cloro livre em cada amostra utilizando Equação 1.

$$
\mathrm{TCL}=\mathrm{Vt} \times \mathrm{Fc} \times 3,546 \times 2,5 /
$$

Na qual:

(Equação 1)

$\mathrm{TCL}=$ Teor de cloro livre

$\mathrm{Vt}=$ média do volume consumido de tiossulfato de sódio $0,1 \mathrm{~N}$ $(1,06)$

$\mathrm{Fc}=$ Fator de correção do tiossulfato de sódio $0,1 \mathrm{~N}$

\section{3,546 = Miliequivalente do cloro}

2,5 = Porcentagem da amostra das águas sanitárias

Todas as análises foram realizadas em triplicatas e foram utilizadas a média aritmética dos volumes gastos. Para a análise estatística das variáveis testadas utilizou-se a análise de variância (ANOVA), seguida pelo teste de Tukey e Dunnet ao nível de significância de $5 \%(p<0,05)$.

\section{DETERMINAÇÃO DO PH}

Para a determinação do pH das soluções, utilizou-se um aparelho digital peagâmetro (marca Digimed, modelo DM 22), devidamente calibrado em temperatura ambiente com solução tampão $\mathrm{pH} \mathrm{4,62} \mathrm{e} \mathrm{6,76.} \mathrm{O} \mathrm{eletrodo} \mathrm{de} \mathrm{medição} \mathrm{foi} \mathrm{imerso}$ em cada amostra de água sanitária até a leitura do $\mathrm{pH}$ apresentar-se estabilizada. Os valores do $\mathrm{pH}$ foram registrados numa ficha laboratorial no momento da leitura, ambos indicados no display do equipamento após 3 leituras realizadas em cada amostra.

\section{RESULTADOS}

A avaliação do teor de cloro livre das soluções de hipoclorito de sódio na concentração de 2-2,5\% após 90 dias de estudo pode ser observada na Tabela 1.

Observa-se que todas as amostras analisadas perdem cloro ao final dos 90 dias e são diferentes entre si estatisticamente. As soluções S1 e S2 apresentam um teor de cloro livre inicial (tempo 0) abaixo e a solução S4 acima do especificado nas suas respectivas embalagens (Tabela 1 ).

\subsection{AVALIAÇÃO FÍSICO-QUUIMICA DA SOLUÇ̃̃O DE HIPOCLORITO DE SÓDIO EM DIFERENTES TEMPOS DE USO E ACONDICIONAMENTO}

Tabela 1 - Avaliação do Teor de Cloro Livre após 90 dias

\begin{tabular}{lccccccr}
\hline Amostras & \multicolumn{5}{c}{ Tempo (dias) } \\
& $\mathbf{0}$ & $\mathbf{7}$ & $\mathbf{1 4}$ & $\mathbf{2 1}$ & $\mathbf{3 0}$ & $\mathbf{6 0}$ & $\mathbf{9 0}$ \\
\hline S1 Alveja & $0,98 \pm 0,06^{\mathrm{A}}$ & $0,93 \pm 0,04^{\mathrm{A}}$ & $0,80 \pm 0,03^{\mathrm{A}}$ & $0,74 \pm 0,02^{\mathrm{A}}$ & $0,73 \pm 0,02^{\mathrm{A}}$ & $0,73 \pm 0,02^{\mathrm{A}}$ & $0,73 \pm 0,01^{\mathrm{A}}$ \\
S2 cristalina & $1,63 \pm 0,04^{\mathrm{B}}$ & $1,63 \pm 0,01^{\mathrm{B}}$ & $1,46 \pm 0,00^{\mathrm{B}}$ & $1,45 \pm 0,03^{\mathrm{B}}$ & $1,44 \pm 0,02^{\mathrm{B}}$ & $1,44 \pm 0,02^{\mathrm{B}}$ & $1,42 \pm 0,01^{\mathrm{B}}$ \\
Sr-Gbarbosa & $2,37 \pm 0,06^{\mathrm{C}}$ & $2,35 \pm 0,01^{\mathrm{C}}$ & $2,21 \pm 0,00^{\mathrm{C}}$ & $2,21 \pm 0,00^{\mathrm{C}}$ & $2,19 \pm 0,02^{\mathrm{C}}$ & $2,19 \pm 0,02^{\mathrm{C}}$ & $2,09 \pm 0,00^{\mathrm{C}}$ \\
S4-Brilux & $2,94 \pm 0,17^{\mathrm{D}}$ & $2,93 \pm 0,09^{\mathrm{D}}$ & $2,80 \pm 0,06^{\mathrm{D}}$ & $2,79 \pm 0,02^{\mathrm{D}}$ & $2,79 \pm 0,04^{\mathrm{D}}$ & $2,70 \pm 0,02^{\mathrm{D}}$ & $2,67 \pm 0,02^{\mathrm{D}}$ \\
S5-Qboa & $2,45 \pm 0,03^{\mathrm{C}}$ & $2,44 \pm 0,02^{\mathrm{C}}$ & $2,36 \pm 0,03^{\mathrm{E}}$ & $2,32 \pm 0,04^{\mathrm{E}}$ & $2,32 \pm 0,00^{\mathrm{E}}$ & $2,32 \pm 0,00^{\mathrm{E}}$ & $2,28 \pm 0,04^{\mathrm{E}}$ \\
S6-Miala & $2,43 \pm 0,07^{\mathrm{C}}$ & $2,32 \pm 0,09^{\mathrm{C}}$ & $2,30 \pm 0,07^{\mathrm{C}, \mathrm{E}}$ & $2,22 \pm 0,03^{\mathrm{C}}$ & $2,20 \pm 0,06^{\mathrm{C}}$ & $2,19 \pm 0,06^{\mathrm{C}}$ & $2,16 \pm 0,01^{\mathrm{F}}$ \\
\hline
\end{tabular}

Letras maiúsculas e iguais na mesma linha ou coluna indicam valores estatisticamente iguais para $p<0,05$.

Fonte: Dados da pesquisa, 2014. 
As soluções S3, S5 e S6 são estatisticamente iguais no tempo 0 e 7 dias, apesar de possuírem diferentes teores de cloro. A partir do 140 dia até os 60 dias as soluções S3 e 66 permanecem estáveis e a solução 55 só difere a partir do 70 dia, enquanto a S6 a partir dos 60 dias (Tabela 1).
O Gráfico 1 mostra em percentagem uma redução no teor de cloro livre em todas as soluções ao final de 90 dias. A maior e menor perda foi verificada na Solução 1 (S1) e Solução 5 (S5), respectivamente.

\section{Gráfico 1 - Perda do Teor de Cloro Total em percentagem de cada amostra após 90 dias}

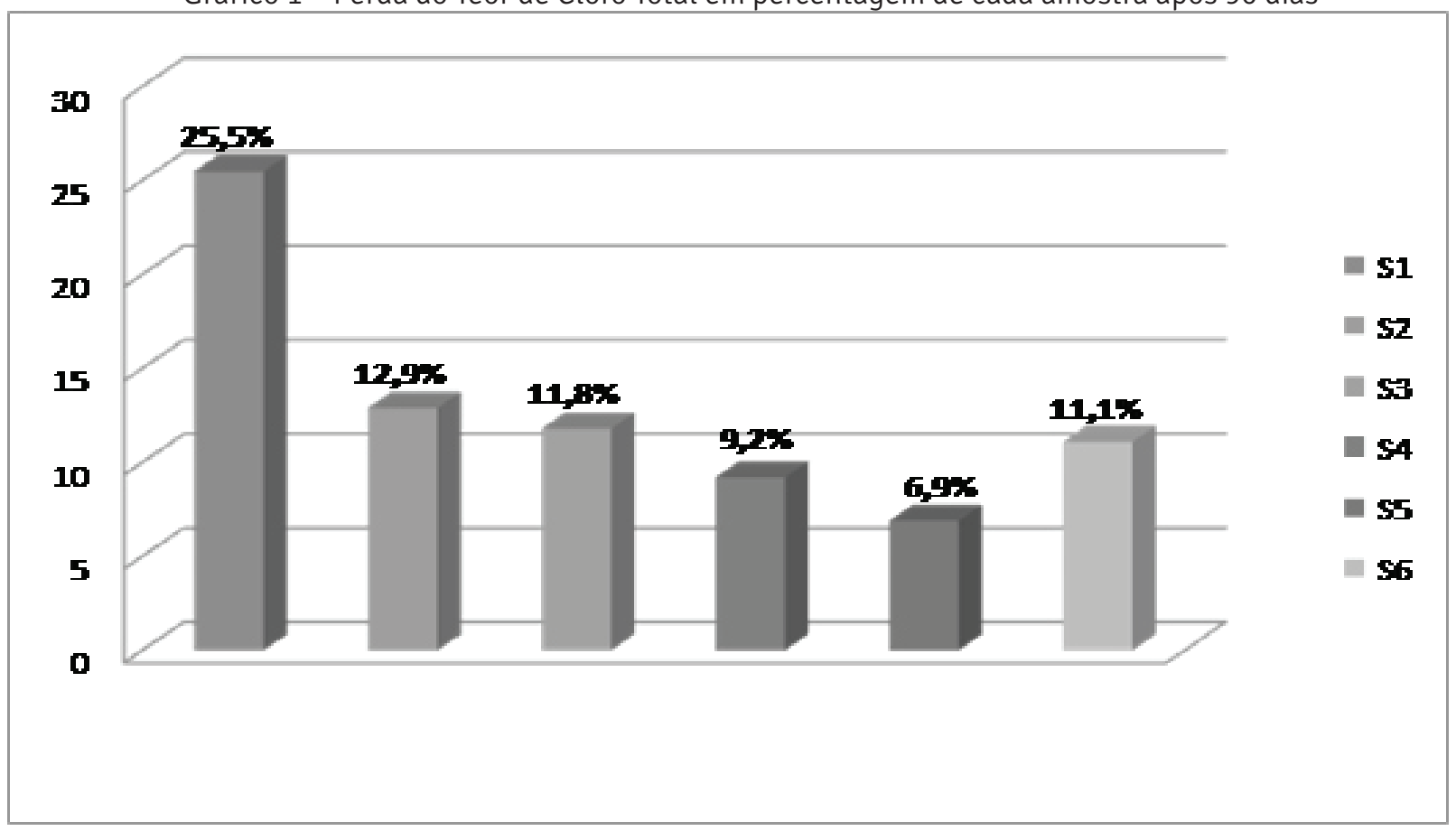

Fonte: Dados da pesquisa, 2014.

$\mathrm{Na}$ Tabela 2, verificou-se o potencial hidrogeniônico $(\mathrm{pH})$ das amostras de hipoclorito de sódio na concentração de 2-2,5\%. Observou-se que todas as soluções apresentaram um pH acima de 10 em todo o estudo.

Tabela 2 - Valores de pH em função do tempo pesquisado

\begin{tabular}{lccccccc}
\hline Soluções & \multicolumn{7}{c}{ Tempo (dias) } \\
\cline { 2 - 8 } & $\mathbf{0}$ & $\mathbf{7}$ & $\mathbf{1 4}$ & $\mathbf{2 1}$ & $\mathbf{3 0}$ & $\mathbf{6 0}$ & $\mathbf{9 0}$ \\
\hline S1 & 11,44 & 11,44 & 11,17 & 11,82 & 10,50 & 12,26 & 12,73 \\
S2 & 12,12 & 12,48 & 12,26 & 12,35 & 11,48 & 12,95 & 12,65 \\
S3 & 12,06 & 12,48 & 12,01 & 12,59 & 11,48 & 13,05 & 12,40 \\
S4 & 12,80 & 11,94 & 11,77 & 12,36 & 11,40 & 12,95 & 12,65 \\
S5 & 12,59 & 12,66 & 11,78 & 12,55 & 11,48 & 12,92 & 12,30 \\
S6 & 12,03 & 12,82 & 12,19 & 12,84 & 11,26 & 12,92 & 12,35 \\
\hline
\end{tabular}

Fonte: Dados da pesquisa, 2014. 


\section{DISCUSSÃO}

A seleção de uma substância irrigadora de canais radiculares impõe um rigoroso controle de qualidade (ESTRELA et al., 2002). A verificação de propriedades físico-químicas e antimicrobianas é essencial, pois todo material para emprego clínico necessita ser constantemente bem avaliado, razão pela qual analisamos seis soluções de hipoclorito de sódio na concentração de 2-2,5\% (águas sanitárias), de diferentes procedências com o intuito de verificar o teor de cloro livre e $\mathrm{pH}$ das mesmas.

A concentração do hipoclorito de sódio utilizado na endodontia pode variar de 0,5\%-5,25\% de cloro livre disponível. Enquanto o mesmo pode ser preparado e acondicionado comercialmente para uso terapêutico, é comum em muitos países ter a água sanitária doméstica (diluída ou não) sendo utilizada como irrigador endodôntico (CLARKSON; PODLICH; MOULE, 2003). Muitas vezes, no Brasil, o cirurgião-dentista não tem acesso a dentais ou farmácias de manipulação para adquirir as soluções irrigantes à base de hipoclorito de sódio. Por este motivo, a água sanitária apresenta-se como um substituto de fácil obtenção em locais distantes dos grandes centros, além do baixo custo (NICOLETTI; BAEZA LOPES; MAGALHÃES, 1995).

Embora existam diversos métodos para avaliar o teor de cloro, a escolha pela titulometria se faz pelo fato de ser amplamente empregado para esses experimentos. Trata-se de um método seguro e utilizado em diversos estudos (BARATTO FILHO, 2001; BORIN et al., 2006; CARVALHO JÚNIOR et al., 2000; RUTALA et al., 1998; SÓ et al., 2004).

Considerando o prazo de validade de seis meses das águas sanitárias, das seis soluções analisadas, duas apresentaram teor de cloro livre abaixo do ideal (S1 e S2) no início do estudo (Tempo 0) com perdas de $60,8 \%$ e $34,8 \%$ respectivamente. Neste caso, supõe-se que a forma de armazenamento e/ou fabricação pode ter sido o principal fator de perda do cloro. De acordo com a United States Pharmacopeia (2008), essas soluções não apresentam padrões quimicamente aceitáveis para desempenharem corretamente suas funções, sendo a dissolução tecidual um dos requisitos primordiais para o sucesso do tratamento endodôntico (RUTALA et al., 1998). Consequentemente, isto pode comprometer toda a terapêutica endodôntica, levando ao insucesso do tratamento. Por outro lado, as soluções S3, S5 e S6 apresentaram teor de cloro livre dentro dos padrões da embalagem no início do estudo o que garantiria sua efetividade no tratamento endodôntico.

Alguns fabricantes produzem soluções com teor de cloro acima do especificado nas embalagens para assegurar a potencialidade do produto por mais tempo. Isto foi verificado na amostra S4 no início e ao final dos 90 dias, o que corrobora com os resultados encontrados nos estudos de Borin e outros autores (2006) e Filho (2008). No entanto essa solução mesmo apresentando um teor acima do ideal, pode levar ao insucesso endodôntico, já que soluções com grandes concentrações quando extravasadas para o periápice, geram necrose de tecidos, edemas e sintomatologia dolorosa (LUDWIG et al., 2006).

Segundo Pécora, Murgel, Savioli, Costa, Vansan e outros autores (1987) as soluções de hipoclorito são instáveis por natureza e perdem seu teor de cloro com o passar do tempo. No presente estudo observou-se que, independente do local de acondicionamento (geladeira e temperatura ambiente), o teor de cloro livre de cada solução foi maior na primeira semana de estudo do que ao final dos 90 dias.

A razão para acondicionar as soluções em geladeira por 12 horas justifica-se pelo fato de que quando armazenadas neste local proporciona uma maior estabilidade e controle sobre o produto. Já que alguns trabalhos mostraram uma perda de cloro lenta em função do acondicionamento em refrigerador (PÉCORA, ESTRELA, 2004; SIRTES et al., 2005; TANOMARU et al., 2005).

De acordo com Siqueira (2000) as soluções de hipoclorito de sódio possuem maior efeito bactericida quando em $\mathrm{pH}$ próximo do neutro ou básico. Ao se trabalhar com soluções em pH básico como neste 
estudo, o potencial irritativo do hidróxido de sódio e alto poder de dissolução acaba atuando de maneira decisiva como bactericida, apesar de não saber a concentração inibitória mínima dessas soluções frente a diferentes microorganismos (ESTRELA et al., 2002).

Neste estudo, conforme a Tabela 2, o valor do $\mathrm{pH}$ esteve sempre acima de 10 durante todo o experimento. Valores estes recomendados para soluções de hipoclorito de sódio, já que as mesmas se tornam mais estáveis com liberação mais lenta do cloro. Trabalhos de Marchesan e outros autores (1998), Estrela e outros autores (2002) e Carvalho Júnior e outros autores (2000) sugerem que o pH da solução deva ser maior que 9 para manutenção de suas propriedades.

Determinar a causa específica do baixo teor de cloro das soluções S1 e S2 é difícil, já que vários são os fatores determinantes na decomposição das soluções de hipoclorito de sódio. A qualidade da água utilizada também pode ser outro fator importante, pois a presença de íons metálicos catalisa a decomposição das soluções, assim como o acondicionamento em locais inadequados durante a fabricação (LOPES; SIQUEIRA JÚNIOR, 2004).

\section{CONCLUSÕES}

Diante dos resultados registrados neste estudo, pode-se concluir que:

- Independente do acondicionamento, a perda de cloro de todas as amostras é dependente ao fator tempo.

- Quanto mais rápido utilizar as soluções de hipoclorito de sódio na irrigação dos canais radiculares, maiores serão as vantagens de suas propriedades físico-químicas.

- AssoluçõesS5(Qboa $\left.{ }^{\circledR}\right), S 6\left(\right.$ Miala $\left.^{\circledR}\right)$ eS3(Gbarbosa $\left.{ }^{\circledR}\right)$, apresentaram teores de cloro livre dentro dos padrões especificados nas embalagens ao final dos 90 dias de estudo, sendo efetivas para o tratamento endodôntico.
- Sugere-se o seguinte protocolo de uso para o hipoclorito de sódio na concentração de 2-2,5\% utilizado para fins terapêuticos: acondicionamento em refrigerador após o uso; aquisição mais próxima da data de fabricação; dentro do prazo de validade e uso por no máximo três meses (90 dias).

- É necessária uma fiscalização mais rigorosa desses produtos pelos órgãos reguladores desde a fabricação até sua distribuição e consumo, independente de sua procedência, para que seja usada de maneira segura pelo cirurgião-dentista.

\section{REFERÊNCIAS}

BARATTO-FILHO, F. Análise comparativa entre o método de titulometria e volumetria para determinação do teor de cloro ativo das soluções de hipoclorito de sódio. Rev Odontol UNAERP, p.99-104, 2001.

BORIN G, MELO TAF, BECKER NA, OLIVEIRA EPM, QUEIRÓZ MLP. Análise da concentração e do pH de diferentes soluções de hipoclorito de sódio encontradas no mercado. Rev Stomatos. 2006, 12(23):29-34.

BORIN G, OLIVEIRA EPM, BECKER NA. A história do hipoclorito de sódio e a sua importância como substância auxiliar no preparo químico mecânico de canais radiculares.

Rev Endod Pesq e Ens On Line, 3(5):1-5, 2007.

CARVALHO JÚNIOR JN, et al. Análise do teor de cloro ativo, pH e tensão superficial de diferentes marcas de soluções de hipoclorito de sódio encontradas no mercado. Rev de Odontol Univ Ribeirão Preto, 3(2):53-59, 2000.

CARVALHO MGP, et al. Avaliação do teor de cloro ativo presente em soluções de hipoclorito de sódio após armazenamento. Rev Stomatos, 9(16):29-35, 2003.

CLARKSON, AJ; PODLICH, RM; MOULE, AJ. The shelf-life of sodium hypochlorite irrigating solutions. Aust Dent J, 46(4): 269-275, 2001. 
CLARKSON, AJ; PODLICH, RM; MOULE; SAVAGE NW. A survey of sodium hypochlorite use by general dental practioners and endodontists in Australia. Aust Dent J, 48(1): 20-6, 2003.

ESTRELA, C; ESTRELA, CRA; CARVALHO, AL; GONELLA, ALPF; PÉCORA, JD. Controle microbiano e químico de diferentes soluções de hipoclorito de sódio. Rev Bras Central, 11(31): 16-21, 2002.

ESTRELA, C; ESTRELA, CRA; BARBIN, EL; SPANO, JCE; MARCHESAN, MA; PÉCORA, JD. Mechanism of action of sodium hypochlorite. Braz Dent J, 13(2):113-7, 2002.

FILHO, PR. Avaliação do teor de cloro ativo das soluções de hipoclorito de sódio. Rev Cons Reg Minas Gerais, 8 (1):54-9, 2002.

LOPES, HL; SIQUEIRA JUNIOR, JF. Substâncias químicas empregadas no preparo dos canais radiculares. Endodontia Biologia e Técnica. 2.ed. Rio de Janeiro: Guanabara Koogan, 2004.

LUDWIG, A; HOFFMEISTER, MK; IRALA, LED; SALLES, AA; LIMONGI, O; SOARES, RG. Análise da concentração de cloro ativo e $\mathrm{pH}$ em amostras de hipoclorito de sódio 1\%. Rev Sul Bras Odontol, 4(1):29-34, 2006.

MARCHESAN, MA; SOUZA, RA; GUERISOLI, DMZ; SILVA, RS; PÉCORA, JD. Análise de algumas propriedades físico-químicas das águas sanitárias encontradas no mercado brasileiro. Rev Bras Odontol, 5(55):301-3, 1998.

NICOLETTI, MA; BAEZA LOPES, MF; MAGALHÃES, JF. Determinação do prazo de validade de soluções comerciais de hipoclorito de sódio expostas a níveis de luminosidade. Rev Inst Ciênc Saúde, 13(2):59-62, 1995.

PÉCORA, JD, MURGEL, CAF, SAVIOLI, RN, COSTA, WF, VANSAN, LP. Estudo sobre o shelf life da solução de Dakin. Rev Odont USP, 1(1): 3-7, 1987.
PÉCORA, JD; ESTRELA, C. Hipoclorito de sódio. Ciência Endodôntica. São Paulo: Artes Médicas, 2004.

REISS-ARAUJO, C; SOUZA, VS; RIOS, MA; ALBUQUERQUE, DS; BARATTO-FILHO, FB; LIMONGI, O. Capacidade de Dissolução Tecidual do Hipoclorito de Sódio em diferentes concentrações. Rev ABO Nac, 14(4):237-241, 2006.

RUTALA WA, et al. Stability and bactericidal activity of cholorine solutions. Infect Control Hosp Epidemiol, 1998, 19(5):323-27.

SIQUEIRA, EL. Estabilidade química da solução de hipoclorito de sódio a 0,5 \% p/v. Ecler Endodontics, 2(3), 2000.

SIRTES, G; WALTIMO, T; SCHAETZLE, M; ZEBNDER, M. The effects of temperature on sodium hypochlorite short-term stability, pulp dissolution capacity, and antimicrobial efficacy. Journal of Endodontics, 31(9):669-671, 2005.

SÓ, MVR, LAZZARI, K; FELICETTI, M; VIEGAS, APK; VIER, FV; SALLES, AA. Efeito do abaixamento e elevação da temperatura sobre o teor de cloro ativo das soluções de hipoclorito de sódio a 1\%. J Bras Endod, 5(17):94-97, 2004.

TANOMARU, JMG; RODRIGUES, VMT; TANOMARU FILHO, M; SPOLIDORIO, DMP; ITO, IY. Avaliação in vitro da atividade antimicrobiana de soluções irrigadoras empregadas em endodontia. Rev Paul Odontol, 27(1):38-40, 2005.

United States pharmacopeia/national formulary. usp $32 \mathrm{nf}$ 27, Rockville: United States Pharmacopeia Convention, Inc., 2008.

VENTURA, ACA; SESTARI, V; COLLESI, RR; SAMPAIO, JMP. Determinação do teor de cloro ativo nas soluções de hipoclorito de sódio: visão atual do problema. Rev Paul de Odontol, 24(4):24-28, 2002. 
1. Especialista em Endodontia pela ABO-SE (Associação Brasileira de Odontologia de Sergipe). E-mail: odontobreno@yahoo.com.br

2. Doutora em Endodontia pela UPE (Universidade de Pernambuco); Professora Adjunta de Endodontia da UEFS-BA (Universidade Estadual de Feira de Santana-Ba).E-mail: endoreiss@yahoo.com.br

Recebido em: 24 de Fevereiro de 2014 Avaliado em: 11 de Março de 2014 Aceito em: 14 de Julho de 2014
3. Doutora em Ciências Farmacêuticas pela USP/FCFRP; (Universidade de São Paulo/Faculdade de Ciências Farmacêuticas de Ribeirão Preto); Professora Titular de Controle de Qualidade Físico-Químico da UNIT. E-mail: juliana@itp.org.br 